\title{
A Case Study on BioChannel Partner: How Can the Sales Turnover of BioChannel Partners' Online Services Be Increased?
}

\author{
Fabiha Enam ${ }^{1 *}$, Marushat Bin Sakhawat ${ }^{2}$, M. Mamoon Al Bashir ${ }^{3}$ \\ ${ }^{1}$ BRAC Business School, BRAC University, Dhaka, Bangladesh \\ ${ }^{2}$ Bangladesh University of Professionals (BUP), Dhaka, Bangladesh \\ ${ }^{3}$ School of Business, Canadian University of Bangladesh, Dhaka, Bangladesh \\ Email: *enam.fabiha@gmail.com
}

How to cite this paper: Enam, F. and $\mathrm{Al}$ Bashir, M.M. (2019) A Case Study on BioChannel Partner: How Can the Sales Turnover of BioChannel Partners' Online Services Be Increased? Journal of Human Resource and Sustainability Studies, 7, 72-97. https://doi.org/10.4236/jhrss.2019.71006

Received: December 24, 2018

Accepted: March 25, 2019

Published: March 28, 2019

Copyright $\odot 2019$ by author(s) and Scientific Research Publishing Inc. This work is licensed under the Creative Commons Attribution International License (CC BY 4.0).

http://creativecommons.org/licenses/by/4.0/

\begin{abstract}
Purpose: BioChannel Partners Ltd. (BCP) is a premier supplier of company matchmaking services in the Life Science industry that assists laboratory product suppliers to increase their export sales by identifying the best possible distributors. The study focuses on increment of the sales turnover of BioChannel Partners' on-line business. Design/methodology/approach: The research is conducted in two phases: primary research and secondary research. The objective of both phases is to identify the reasons for the low sales of BioChannel Partners' online services. Secondary research represents the first part of the research phase and includes an internal and external analysis of the company. Primary research involves a thorough study of the feedback collected from the primary research to reveal problem areas. The other objective is analysing what should be done to increase the sales turnover of the on-line services of BCP. This involves making recommendations for improvement based on the suggestions gathered from the customers directly through in-depth telephone interviews and online surveys. Findings: The results of the research phase have identified four major problem areas. First, there are prevailing customer habits of selecting distributors on a personal level via references and networking. Second, BCP's on-line service Silver does not attract customers due to less value for money. Third, BCP only makes use of few market research to adjust product and pricing to customer preferences. Fourth, the benefits of the on-line services are not clearly communicated, whereas the web design confuses the issue even more. Originality/value: This paper provides BCP with a guideline to address its problems and increase its sales turnover by attracting and retaining more customers. These recommendations are relevant for most companies in this industry and can be utilised to improve the functioning of the organization.
\end{abstract}




\section{Keywords}

On-Line Business, E-Marketing Strategy, Management Solution, Life Science Industry

\section{Introduction}

How to increase the sales turnover of the new introduced on-line services of BioChannel Partners Ltd. (BCP)? This represents the leading question and topic of the following report. For BCP, a highly experienced company within the Life Science industry, this question has developed into an important issue.

BCP, a premier supplier of company matchmaking services in the Life Science industry, recently introduced an on-line business consisting of the services $\mathrm{BCP}$ Bronze and Silver to target a larger audience of customers, decrease human interaction and to increase the awareness of more expensive personal search. In contrast to the latter search services, the on-line business struggled in terms of subscriptions.

In order to find an answer to the major question of the report, first primary and secondary research are conducted to identify the reasons for the on-line services' low sales turnover. In this context, a high emphasis is put on direct feedback from existing and potential customers as they finally buy/do not buy BCP's services. Both the primary analysis and secondary analysis are based on research theories. The latter will be proposed in form of a pro-active approach to actively target new customers by following an e-marketing strategy. The recommendations finally provide a solution to the overall research question.

The paper is structured in a logical way according to the progress of the project. Chapter 2 consists of a review of the relevant literature in this field. Chapter 3 provides the overall project methodology, before Chapter 4 deals with the entire secondary analysis. Following, Chapter 5 comprises primary research including qualitative and quantitative analyses. The results of the previous chapters are summarised in Chapter 6 and recommendations and respective implementations are provided. Finally, conclusions round up the report in Chapter 7.

\section{Literature Review}

The purpose of this research is to increase the sales of BioChannel Partners Ltd. Online marketing is a valuable tool in the modern market to reach the target customer and thus, increase sales. Online marketing offers some distinct advantages as opposed to traditional marketing. One of the notable benefits of online marketing is it's prevalence as a communication channel between buyers and sellers. It facilitates customer information gathering via surveys and provides valuable insight for new product development and customer relationship management [1]. Online marketing improves buyer seller interactivity and overall buying experience [2]. It can also be used as a transaction channel. Online mar- 
keting improves visibility and helps reach a much bigger customer base [3]. It also increases revenues by exploiting cross selling opportunities [4]. Online marketing streamlines transaction processing. Which in result reduces task complexity, paperwork and transaction costs. It also improves flexibility. Internet marking has a unique ability to serve both as a transaction and distribution medium. Using the web as a distribution channel significantly lowers the delivery cost [5].

In modern e-commerce environment, website quality plays a huge role in customer conversion and retention [6]. One of the main objectives of every e-commerce websites is to attract first time purchase and repeated visits from customers [7].

Lindenberg and Neerinex (1999) [8] suggested a usability testing of web based services based on measures such as effectiveness, efficiency and satisfaction [8]. Previous studies on usability have indicated that improved usability is associated with enhanced accuracy, reduction in errors, positive attitude towards target system, and increased usage [9] [10]. However, such indicators are outcomes of usability rather than measurements of website quality dimensions or website attributes per se.

Several studies have emphasized the importance of service quality, customer satisfaction, and customer experience in the virtual environment [11] [12]. Various website qualities influence customers to adhere to a certain website. Factors such as information quality, interactivity, playfulness [13]; appearance, content quality; website design, order fulfilment, communication [14]; information quality, transaction speed, user-friendliness and security [15] [16] can all be attributed to customer preference for a certain website.

With the growing use of e-commerce websites, customer interaction through digital channels is increasing. Marketers have deemed it necessary to track these interactions to measure their performance [17]. For this purpose, firms must adopt Web analytics (WA), defined as "the measurement, collection, analysis and reporting of Internet data for the purposes of understanding and optimizing Web usage" [18]. Website Analytics data can be used to understand online customer behavior, measure customer responses to digital marketing and as a result, digital marketing can be optimized to foster customer behavior that benefits the business [19]. Web Analytics is more beneficial for businesses in which transactions are processed online [20].

Managerial relevance for market segmentation lies in its ability to partition the consumers into homogenous groups that differs based on their purchase behavior [21]. A well formulated and clearly defined positioning strategy positively impacts the company performance in terms of profitability and efficiency [22] [23] [24].

\section{Methodology}

The approach to solve the main objective of the report composes of several steps, which are presented in the following paragraphs. The achievement of each step 
will finally lead to an answer to the overall project assignment. Figure 1 clarifies the different steps graphically.

1) Identification of the reasons for low sales turnover of $B C P$ 's on-line services

The first step will be realised by conducting primary and secondary analysis as indicated in Figure 1. In this context several theories will be utilised comprising of McKinsey's 7-S Model (company analysis), e-marketing books (website analysis) and theoretical guidelines on how to conduct primary research at best (Interviews and surveys). The goal is to identify internal and external reasons for the low sales turnover of BCP's on-line services by considering not only own secondary research findings, but also direct feedback from existing and potential customers of the company (primary analysis).

2) Evaluation of research results

The second step will summarise and evaluate major research findings from the previous step. In this context only the most relevant information regarding the overall objective will be assembled from different research methods and finally presented in form of a SWOT-Matrix. Additionally this step will serve as a link between the research and the recommendation stage, thus enhance the overview and understanding of the project.

3) Determination of recommendations to increase the sales turnover of $B C P S$ on-line services

Building up on the previous results this step proposes recommendations in form of a pro-active approach. On one side, the pro-active approach thereby includes an e-marketing strategy (SOSTAC) to actively target new customers and increase the traffic on the website. Furthermore, additional ways to generate sales will be recommended based on benchmarking.

\section{4) Implementation of proposed recommendations}

The last step of the project deals with the implementation of the previously proposed recommendations. In this way a guideline (implementation plan) shows what activities need to be done by whom at what time. Furthermore, a
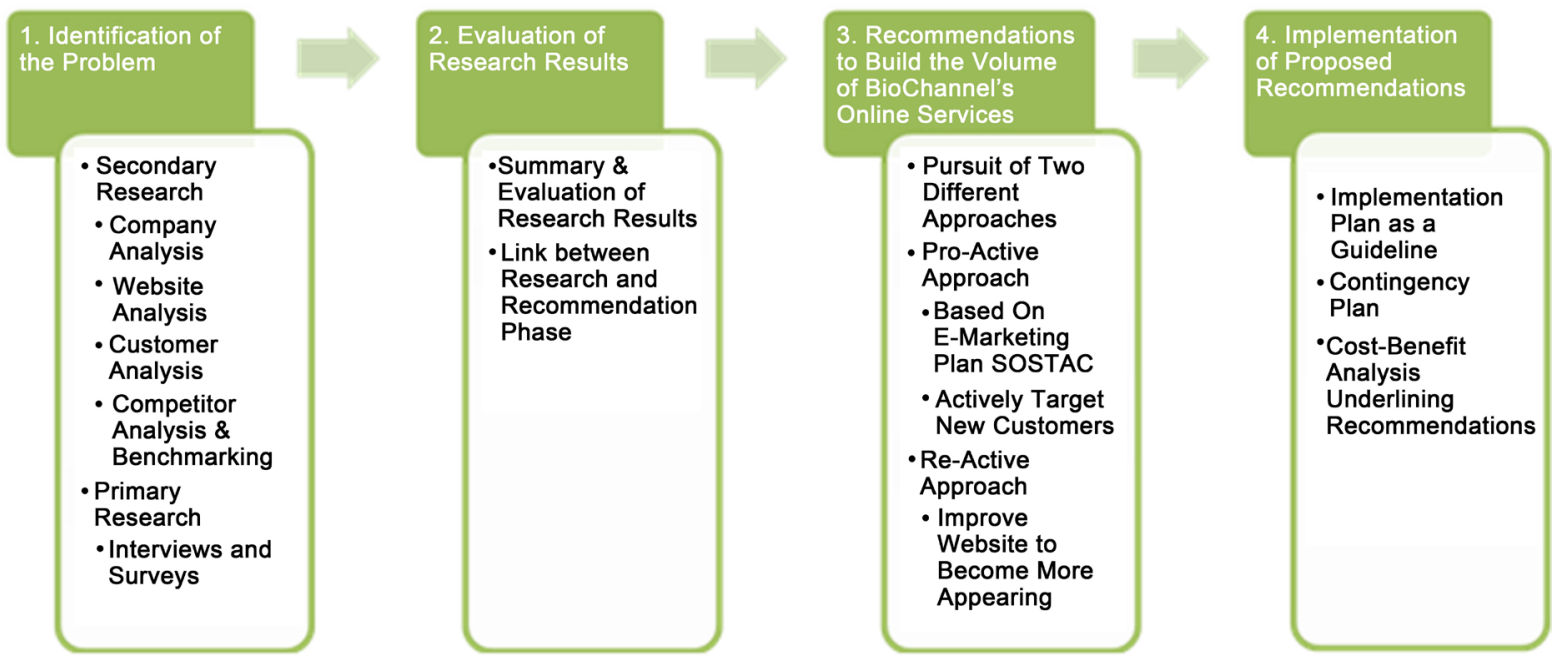

Figure 1. Project approach. 
contingency plan considers risks of the implementation and suggests respective measure for prevention.

\section{Research design}

The research design is an important step towards carrying out the actual primary and secondary research. In this context there are two phases that should be undertaken to reach satisfactory results in the end. The research design starts with defining the problem, which is broken down into the Market Decision Problem-What should be done to increase the sales turnover of BCP's on-line services and the Market Research Problem-Identification of the reasons for the low sales of on-line business with a focus on BCP's strengths, weaknesses (internal), opportunities and threats (external).

The next step defines the Research Objectives by retrieving data from in-depth telephone interviews with three existing and three potential customers, from secondary research results and from discussions with Sharon Eaton. These objectives will act as "causes" for the low sales turnover, which will be generalised by addressing them to a larger audience through surveys.

The in-depth interviews and secondary research, which are conducted in the first phase, will be part of the Qualitative Research. The secondary research thereby has high importance since most objectives for the research are drawn from this process and would act as a crucial step to understand the project.

The second phase in the research process is known as Descriptive Research. Respondents are manufacturers within the Life Science industry. Thereby a questionnaire with close-ended questions of 10 questions at maximum will form the survey. The questionnaire mainly addresses identifying current problems of the customers and their recommendations. Several modes will be used to distribute the survey to obtain sufficient and timely responses. The last step consists of the data collection and analysis. The given data will thereby be presented in graphical form, which is the easiest and less time-consuming way of interpreting retrieved data [25].

\section{Secondary Research}

This chapter represents the first part of the research phase and includes an internal and external analysis. The objective of the chapter is to identify the reasons for the low sales of BioChannel Partners' online services. Some of the results presented in this chapter are further extended by the second part of the research phase (primary analysis) in chapter 5 .

\subsection{Internal Analysis}

The internal analysis will investigate several internal, company-related factors to identify strengths and weaknesses. First, the company will be examined by applying McKinsey's 7S model (The McKinsey Company, 2010). As the database, as previously indicated, represents the basis for BCP's online services, an analysis regarding its design, functioning and presentation will be included. Afterwards 
the focus will lie on a customer analysis. In this way important information about their behaviour and preferences in respect of BCP's online services can be collected.

Analysis of BioChannel Partners internal strengths and weaknesses

The following analysis of BioChannel Partners is based on McKinsey's 7S-Model. The analysis distinguished between the company's "hard-factors": strategy, structure and systems and BCP's "soft-factors": Skills, staff, style and shared values. The following Table 1 further includes major findings of an analysis of BCP's on-line services Bronze and Silver.

\subsection{Website Analysis}

\section{Evaluation BioChannel Partners website in terms of general website format}

The design of the website defines the e-experience of the site visitor. The website of BioChannel Partners plays an inevitable role in operating the online services Table 2. Analysing the website we found some irrelevant content like chat room, current achievements etc. However, there are also some features that can be added such as a brief history of the organisation, help and press releases.

Several components are essential to the design of a website. Such as elements like colours, graphics, shapes and type styles etc. Colour can affect readability.

Table 1. 7-S analysis.

\begin{tabular}{|c|c|}
\hline $7 s$ & Key Findings \\
\hline Strategy & $\begin{array}{l}\text { - Maximise profits by producing minimum costs } \\
\text { - Flexible workforce; Part-time now, full-time once demand increased } \\
\text { - Introduction of e-commerce as diversification }\end{array}$ \\
\hline Structure & $\begin{array}{l}\text { - Dependency on Sharon Eaton due to high experience and connections } \\
\text { - Flexible team of part-time staff and consultants }\end{array}$ \\
\hline System & $\begin{array}{l}\text { - Database contains over } 15,000 \text { companies including both, manufacturers and } \\
\text { distributors, from more than } 140 \text { countries } \\
\text { - Online service provide less information compared to personal services }\end{array}$ \\
\hline Skills & $\begin{array}{l}\text { - High experience of workforce within the Life Science industry } \\
\text { - Few utilization of staff-skills at the moment }\end{array}$ \\
\hline Staff & - Ten employees allocated to different functions (e.g. Marketing) \\
\hline Style & $\begin{array}{l}\text { - Encourage team work } \\
\text { - Democratic leadership } \\
\text { - Empowered to take initiative and responsibility }\end{array}$ \\
\hline $\begin{array}{l}\text { Shared } \\
\text { Values }\end{array}$ & - Liberal and democratic working environment \\
\hline Products & $\begin{array}{l}\text { - Detailed search criteria within database } \\
\text { - Verification of purchased profiles within } 24 \text { hours } \\
\text { - Product pricing orientates on internal costs } \\
\text { - Product discounts are available } \\
\text { - Once logged-in, there is no personal web space } \\
\text { - Globally accessible }\end{array}$ \\
\hline
\end{tabular}

Source: Own table. 
Different colour combinations are associated with different meanings. In BCP website Table 3, the colour theme is mainly based on the colour combination of BCP logo. Graphics can make a page look more appealing and interesting. Static and dynamic graphics are both used in BCP website (Rowley, 2002).

Shapes have subtler effect than colours on website design. Type styles also communicate the style, mood and temperament of the site. The type styles are kept simple and easily readable for the users. In BCP, the content of the website is also separated from the database. BCP uses customer relationship management to store the information of its users. Currently BCP website does not have any multimedia component, but it can prove useful to draw attention of users.

Evaluation of BioChannel Partner's Website in terms of Customer Experience

For BioChannel Partners gaining customer trust and satisfaction would require a lot of efforts from effective marketing measures to providing useful services. There can be various elements on the basis of which the customer satisfaction can be analysed like functionality, perception, buying experience, response, trust element etc.

In context of BCP, Functionality of the website/processes is not user-friendly. When it comes to evaluating the Perception of the people regarding BCP's online services, it is difficult to do so since many people are unaware of the benefits of using such services for the purpose of finding distributors. Buying Experience is not as pleasant because the search results may take as many as 24 hours to be delivered. Besides, the buying process can be tedious because of the complicated payment process and stages of finding distributors. Response of the customers may vary but general consensus can be built on certain aspects and so as the disagreement. The Trust Element is an important factor in this case. The

Table 2. Comparison of contents between BCP website and general website.

\begin{tabular}{|c|c|c|c|c|c|c|c|c|c|}
\hline \multirow[b]{2}{*}{$\begin{array}{l}\text { Typical Content of } \\
\text { a website }\end{array}$} & \multicolumn{3}{|c|}{ What's new } & \multicolumn{4}{|c|}{ About the Company } & \multicolumn{2}{|c|}{ Product Information } \\
\hline & $\begin{array}{l}\text { What's been added } \\
\text { since (date) }\end{array}$ & $\begin{array}{c}\text { New } \\
\text { Products }\end{array}$ & $\begin{array}{c}\text { Press } \\
\text { Releases }\end{array}$ & History & $\begin{array}{l}\text { Contact and } \\
\text { key People }\end{array}$ & $\begin{array}{c}\text { Current } \\
\text { achievements }\end{array}$ & Careers & $\begin{array}{c}\text { Services } \\
\text { Description }\end{array}$ & $\begin{array}{l}\text { special } \\
\text { Offers }\end{array}$ \\
\hline BCP's Website & $\checkmark$ & $\checkmark$ & $x$ & $x$ & $\checkmark$ & $x$ & $x$ & $\checkmark$ & $\times$ \\
\hline website & FAQs & Help Desk & \multicolumn{2}{|c|}{ Press Releases } & \multicolumn{2}{|c|}{ Chat Room } & \multicolumn{3}{|c|}{ Bulletin Boards } \\
\hline $\begin{array}{c}\text { BioChannel Partner's } \\
\text { Website }\end{array}$ & $x$ & $x$ & & $\times$ & & $\times$ & & $\checkmark$ & \\
\hline
\end{tabular}

Source: Own table.

Table 3. Comparison of elements in BCP website and general format.

\begin{tabular}{cccccc}
\hline Typical Element of a website & Colours & Graphics & Shapes and type styles & Database & Multimedia Component \\
\hline BioChannel Partner's Website & $\checkmark$ & $\checkmark$ & $\checkmark$ & $\checkmark$ & $\times$ \\
\hline
\end{tabular}

Source: Own table. 
company came long ago in this business by providing personal search services, therefore the reputation company carries with it from personal services has been transferred to the online services resulting in the rise of the trust level of the customers.

Analysing website in terms of usability, accessibility and quality of customer experience.

In terms of Usability, the main purpose of the BCP's online services is to lessen the burden of the personal search services. The website plays a dual role of providing easy search results by subscribing online as well as promoting the offline business of BCP. Having said that, it is more active in the former. The website represents the conversion from offline to online business and thus, contributing to revenue generation along with promoting the brand name.

In Table 4, the BCP online services in one country is provided in the same manner as it does in another but the downside to this is that no efforts have been put to make the website seem local. So for example it may be difficult to generate the interest of the people whose first language is not English if the content on the website is only available in one language i.e. English. Therefore, it might be difficult to achieve search engine optimisation especially in those countries.

\subsection{Customer Analysis}

While "surfing" on a website, visitors leave behind information about their movements and behaviours, which can be tracked by an on-line programme called Google Analytics (Google Inc., 2011). Such information can lead to valuable conclusions about website specific factors such as attractiveness, contents, design and navigation. Hence, Google Analytics is utilised to evaluate visitors' behaviours and movements on BCP's website. In doing so, major findings in regard to different "kinds" of visitors (direct, referred and search engine visitors), benchmarking and webpage contents are presented in a summarised form due to the complex nature of the data provided by Google Analytics.

\section{Primary Research}

The broad objectives of the primary research is 'Identification of the reasons for the low sales turnover of BCP`s on-line business. This involves a thorough study

Table 4. Quality of customer experience on BCP's website.

\begin{tabular}{|c|c|c|c|}
\hline Intangibles & Reliability & Responsiveness & Assurance \& Empathy \\
\hline 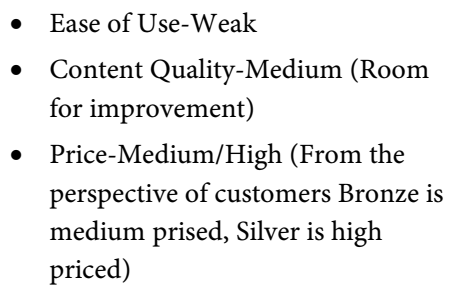 & $\begin{array}{l}\text { - Availability-Good (But } \\
\text { lack behind in terms of } \\
\text { seeming "local") } \\
\text { - Bugs-None }\end{array}$ & $\begin{array}{l}\text { E-mail response or } \\
\text { call-back to a query-Quick } \\
\text { enough } \\
\text { - Fulfilment (Delivery of } \\
\text { orders)-On time (May take } \\
\text { up to } 24 \text { hours as } \\
\text { mentioned on the website) }\end{array}$ & $\begin{array}{l}\text { - Contact with the company-Possible } \\
\text { - Personalise-Currently not provided } \\
\text { (personalised search results but other } \\
\text { than that no other scope for } \\
\text { personalisation) } \\
\text { - Privacy option-Good } \\
\text { - Security option-Good }\end{array}$ \\
\hline
\end{tabular}

Source: (Chaffey, 2009). 
of the feedback collected from the primary research to reveal problem areas other objective is analysing what should be done to increase the sales turnover of the on-line services of BCP. This involves making recommendations for improvement based on the suggestions gathered from the customers directly through in-depth telephone interviews and online surveys.

The primary research is divided into three stages [25]. The first stage is the qualitative research, which involves conducting in-depth telephone interviews with three-potential and three existing customers of BioChannel Partners.

Potential customers in this case are manufacturers, who are registered at BCP's website but are not yet subscribed (bought products) to its online services. This is to identify the reasons for not subscribing and to know their preference.

Existing Customers are registered as well as subscribed users of BCP. The purpose of conducting these interviews is to reveal their feedback in terms of experience in using the online services.

The interviews are conducted with domestic and international customers. In the customer analysis (cf. chapter 4.1.3) the data revealed that there are strong differences in the behaviour of customers from English-speaking and non-English-speaking countries. These differences shall now be considered and further validated. Moreover, in this way a need for local adaptation of BCP's on-line services should be investigated.

The questions have been formulated beforehand and fall under different categories (website, on-line services, competitors, marketing) that relate to every aspect of BCP's on-line business. Please see appendix 7 for respective interviews.

The second stage involves the definition of possible causes for the low sales turnover of BCP's on-line services derived from the in-depth interviews with the customers. In order to check the validity of those causes, they were addressed to a larger audience through online surveys in order to generalise findings.

The third stage of the primary research represents quantitative research. This involves sending out surveys to the Manufactures (Target Customers of BCP) to validate the causes set out in the second stage of the research process. In this context a structured questionnaire is prepared consisting of 10 questions of both objective and subjective nature (See appendix 8 for the questionnaire). The key modes of sending out these online surveys are via E-mails and Social Networking site for the professionals called LinkedIn in order to get sufficient and in-time responses of the respondents. The maximum time allotted for filling out the questionnaire for the survey is 15 days. With approval of Sharon Eaton (owner of BioChannel partners), three Bronze credits have been attached as an incentive to fill out the questionnaires. The expected response rate is $10 \%-12 \%$.

The final step is devoted to summarise the research results. At the end of which we would be able to identify the actual problems/reason for the low sales of the on-line services of BioChannel Partners and recommend appropriate solutions for the company to realise its long term goals of profitability and growth.

Exclusively regarding the primary research, a generic process is followed to 
manage retrieved data as shown in Figure 2. In this context, each step is important to finally obtain the valuable and verified outcome. Explanations to each step are attached in Figure 1.

\subsection{Qualitative Analysis}

This chapter will present the first part of the primary analysis. In the beginning the responses of the interviews will be analysed in a tabular form representing existing and potential customers. A full description of the interview questions can thereby be found in appendix 7. Table 5: Afterwards several findings will be created based on the aforementioned analysis of interview results.

Summarising, the opinions of potential customers, all of them found navigating on the website easy. The rate of return on the website in all cases is low and the most common driving force is search for new distributors. Customers found the content on the website as unclear due to too much unstructured information.

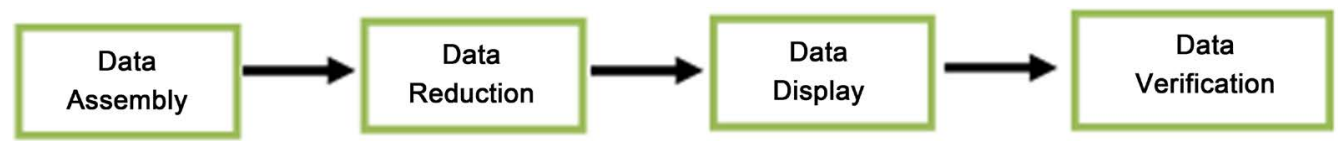

Source: Malhotra and Birks, 2007.

Figure 2. Generic process of qualitative analysis.

Table 5. Results of exploratory analysis-Potential customers.

\begin{tabular}{|c|c|c|c|}
\hline Categories/Criteria & Interviewee 1 & Interviewee 2 & Interviewee 3 \\
\hline $\begin{array}{l}\text { Navigation on the website } \\
\text { - Functioning } \\
\text { - Presentation }\end{array}$ & $\begin{array}{l}\text { Fine } \\
\text { Good }\end{array}$ & $\begin{array}{l}\text { Very Easy } \\
\text { Alright }\end{array}$ & $\begin{array}{l}\text { Reasonable } \\
\text { Good }\end{array}$ \\
\hline $\begin{array}{l}\text { Rate and driving force for } \\
\text { return }\end{array}$ & $\begin{array}{l}\text { Not very often. Email updates about } \\
\text { services can be a driving force }\end{array}$ & $\begin{array}{l}\text { Rare visit in search for new product types (search } \\
\text { criteria) and new distributors }\end{array}$ & $\begin{array}{l}\text { Once a week to find new } \\
\text { distributors }\end{array}$ \\
\hline Content on the website & Alright & Content is not clear & User-friendly \\
\hline Pricing of the services & $\begin{array}{l}\text { Price is value for money with } \\
\text { reference to BCP Bronze }\end{array}$ & Price is expensive with reference to BCP Silver & Very good (BCP Bronze) \\
\hline $\begin{array}{l}\text { Numerous ways to find } \\
\text { distributors }\end{array}$ & Websites and agencies & Recommendations and references from colleagues & $\begin{array}{l}\text { Search engines (like } \\
\text { Google), agencies }\end{array}$ \\
\hline $\begin{array}{l}\text { Source of information } \\
\text { regarding BCP online } \\
\text { services }\end{array}$ & Recommended by others & Personal contact with MD Sharon Eaton & LinkedIn \\
\hline $\begin{array}{l}\text { Reasons for not subscribing/ } \\
\text { buying the services }\end{array}$ & $\begin{array}{l}\text { No requirement for finding } \\
\text { distributors using } \mathrm{BCP}\end{array}$ & No requirement for finding distributors using BCP & $\begin{array}{l}\text { No requirement for } \\
\text { finding distributors } \\
\text { using BCP }\end{array}$ \\
\hline $\begin{array}{l}\text { Suggestions for } \\
\text { improvement }\end{array}$ & $\begin{array}{l}\text { More communication and } \\
\text { interaction channels other than } \\
\text { LinkedIn and Regular e-mail updates }\end{array}$ & $\begin{array}{l}\text { More information required about the services, } \\
\text { incentives/discounts, optional/additional services } \\
\text { through news alerts and e-mail updates }\end{array}$ & $\begin{array}{l}\text { Translation of the } \\
\text { website in Chinese } \\
\text { language }\end{array}$ \\
\hline
\end{tabular}

Source: Own table. 
Most customers preferred BCP Bronze over BCP Silver due to cost effectiveness and more structured information. As a way of finding distributors, potential customers use personal networking, search engines and distributor mangers. They use no other websites like BCP. Networking through LinkedIn and personal contacts of Sharon Eaton are solely responsible for bringing business to the BioChannel Partners. E-mail updates and news alerts regarding BCP services are most desired by the customers in order to drive them to return on the website more often.

Summarising Table 6, existing customers have different opinions about the BCP online services than potential customers. They found the navigation and presentation of the website are unattractive and monotonous. They suggested using more graphics and animation. Customers prefer BCP Bronze over BSP silver because it's affordable. They were highly satisfied with the comprehensiveness and quality of the database and search criteria although they think the result should be quicker. The rate of return on the website varies from customer to customer. They all agreed to a common ground that the main drive force to the website is find new distributors. All of the customers are devoted to BCP and do not use other competitor's website.

Table 6. Results of exploratory analysis-Existing customers.

\begin{tabular}{|c|c|c|c|}
\hline Categories/Criteria & Interviewee 1 & Interviewee 2 & Interviewee 3 \\
\hline $\begin{array}{l}\text { Source of information regarding } \\
\text { BCP online services }\end{array}$ & Search Engine (e.g. Google) & Conference & LinkedIn \\
\hline Relationship with BCP Online services & One month & One year & Six-eight months \\
\hline Navigation on the website Functioning & Alright & Struggle to find information & A little difficult \\
\hline Presentation & Good & $\begin{array}{l}\text { Alright but should be better, } \\
\text { boring and monotonous }\end{array}$ & No response \\
\hline Rate and driving force for return & Monthly To find distributors & Monthly Not sure & Yearly Search for new distributors \\
\hline Product Preference and WHY & Bronze Reasonable Price & Bronze Affordable & Bronze is cost effective \\
\hline Pricing & Reasonable for Bronze but not for silver & Ok for Bronze & Bronze is ok Silver is expensive \\
\hline Search Criteria & Useful & Not useful & Beneficial \\
\hline Database & Good Quality, Up to date & Comprehensive but errors in data & Good \\
\hline \multicolumn{4}{|l|}{ Result } \\
\hline - Satisfactory & Yes & No & Yes \\
\hline - Quick enough & Should be quicker & No response & Not quick enough \\
\hline Competitors of BCP & Never heard & Never heard & Never heard \\
\hline Modes for searching distributors & No response & Conferences, search engine & No other modes \\
\hline Desired Optional Services & Nothing & Nothing & Market Research on nation \\
\hline Overall Suggestions & $\begin{array}{l}\text { Import of data to excel in order to } \\
\text { create tables and work with data }\end{array}$ & Presentation should be improved & $\begin{array}{l}\text { Further breakdown of database } \\
\text { Manufacturer's page, up to } \\
\text { date his activities }\end{array}$ \\
\hline
\end{tabular}

Source: Own table. 


\subsection{Definition of Potential Causes for the Low Sales Turnover of BCP's On-Line Services}

This subchapter represents the second step of the primary analysis. Building up on the results of the interviews, several points of common agreement amongst both potential and existing customers have been found. These points are summarised in the following Table 7 and are directly used as a source for the recommendations.

Despite of many points of common agreement there have also been several disagreements between interviewees. These differences are summarized in the following four causes which portrays the major problems identified by the respondents:

Cause 1: Having never heard about BCP's online services before, customers tend to find it difficult to understand the content on the website

During the interviews, one respondent stated to have never visited BCP's website before. In order to be able to answer the questions he surfed onto the website while simultaneously providing answers. Although he described the contents on the website as good, he was not able to understand BCP's product Silver. Moreover, in the customer analysis random visitors were not attracted by the website and hence, indicate difficulties in understanding the content.

Cause 2: Customers tend to find it difficult to navigate on the website

Interviewees provided different statements about the navigation of the website. Hence, the issue will be examined during the survey in more detail.

Cause 3: The only reason for not using $B C P$ 's online services is. No requirement of the services at a particular point in time

Although there was general consensus amongst potential customers, existing customers provided different feedback about reasons that drive them to return to BCP's website. In addition, this issue represents a highly important point as it might be a major reason why BCP's website has little traffic and return rates. Hence, the finding is examined in the survey.

Cause 4: An additional way to attract customers to register and subscribe is by providing the optional services.

Amongst existing customers optional services were partly welcomed and partly rejected. Since, in addition, potential customers mentioned to improve the

Table 7. Common agreements amongst interviewees.

Interviewees - Points of common agreement

- People only return to the website once interested in finding a new distributor

- BCP Bronze's pricing is value for money

- BCP Silver is too expensive and test results are not beneficial

- Personal networking is mainly used for finding distributors

- There are no potential competitors of BCP. If manufacturers have to use any means of finding distributors through an on-line database, BCP is exclusively used for that purpose

Source: Own table. 
website by adding some sort of optional services, the latter will be examined more closely in the survey.

\subsection{Quantitative Analysis}

The main objective of the project is to increase the sales of the online services for that the company has to identify the reasons behind customers not buying them. As the number of existing customers is currently limited, only potential customers are targeted for the survey. The sample size for the quantitative research is 953 people in total, including 853 people that have access to BCP's profile on LinkedIn and 100 people extracted from BCP's website that have been directly contacted. The total number of respondents amounts 33 which account for the response rate of 3.4\%, who are from all over the world such as UK, USA, France, Germany, India, Israel, China etc. Survey questions and their responses are given in a graphical format below.

Cause 1: "Having never heard about BCP's online services before, customers tend to find it difficult to understand the service content on the website"

First the findings from the interviews Figure 3 and then from the surveys show that most people tend to find it difficult to understand the content related to the services/offerings. It can be due to not hearing about BCPs services beforehand and the structure of the content. However, the above mentioned cause is based on an assumption. Most respondents found the content on the homepage as clear and understandable. Following homepages are Manufacturers overview and BCP Bronze page. The weakest is the content on pricing and BCP silver search which is found at fault and require restructuring. Non-English speaking nationals (India, China and Germany) have been more critical as compare to people belonging

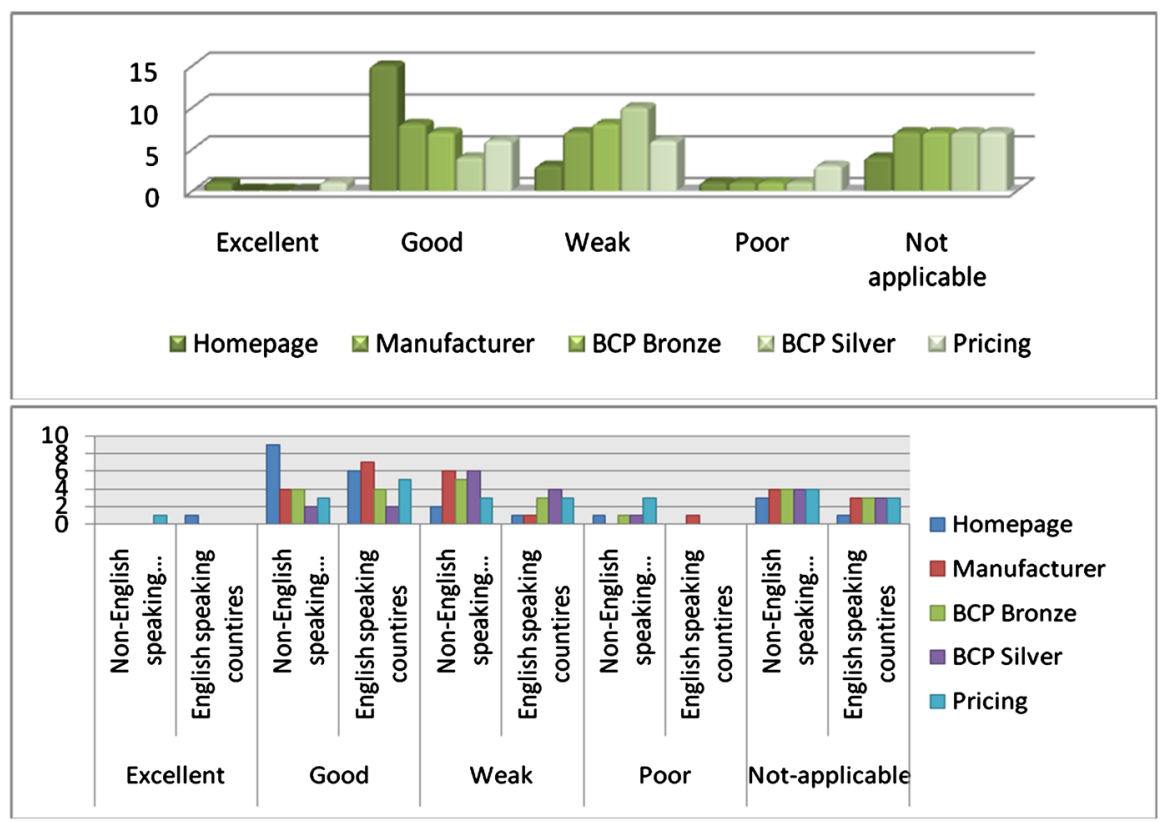

Source: Own Figure.

Figure 3. How do you assess the information on the following pages of BCP's website? 
to the English speaking countries thus supporting the customer analysis done earlier.

Cause 2: "Customers tend to find it difficult to navigate on the website"

From the above graph Figure 4, the analyses show that most respondents find navigation from the homepage to the manufacturer's overview page easy as compare to other pages. Respondents seem to be familiar with the homepage content. Efforts can be put to improve the registration (information and process). Navigation to pricing and services pages for identifying the prices and retrieving information on the services respectively are found to be weak. However, the numbers of non-applicable results reflect that not many customers have visited the website with great interest or with the intention of registering/subscribing therefore weren't able to provide useful feedback to the question. This led to the conclusion that the cause is partly verified from the above evaluation of the responses.

Again, a sharp difference of opinion can be observed between English and Non-English speaking countries. Most critical as well as non-applicable answers come from Non-English speaking nationals.

Cause 3: "The only reason for not using BCP s online services is: No requirement of the services at a particular point in time"

The responses confirm the fact that the key reason behind not using the BCP's online services is "no current requirement" for finding the distributors using an online database like BCP Figure 5. On the other hand, pricing of the services are

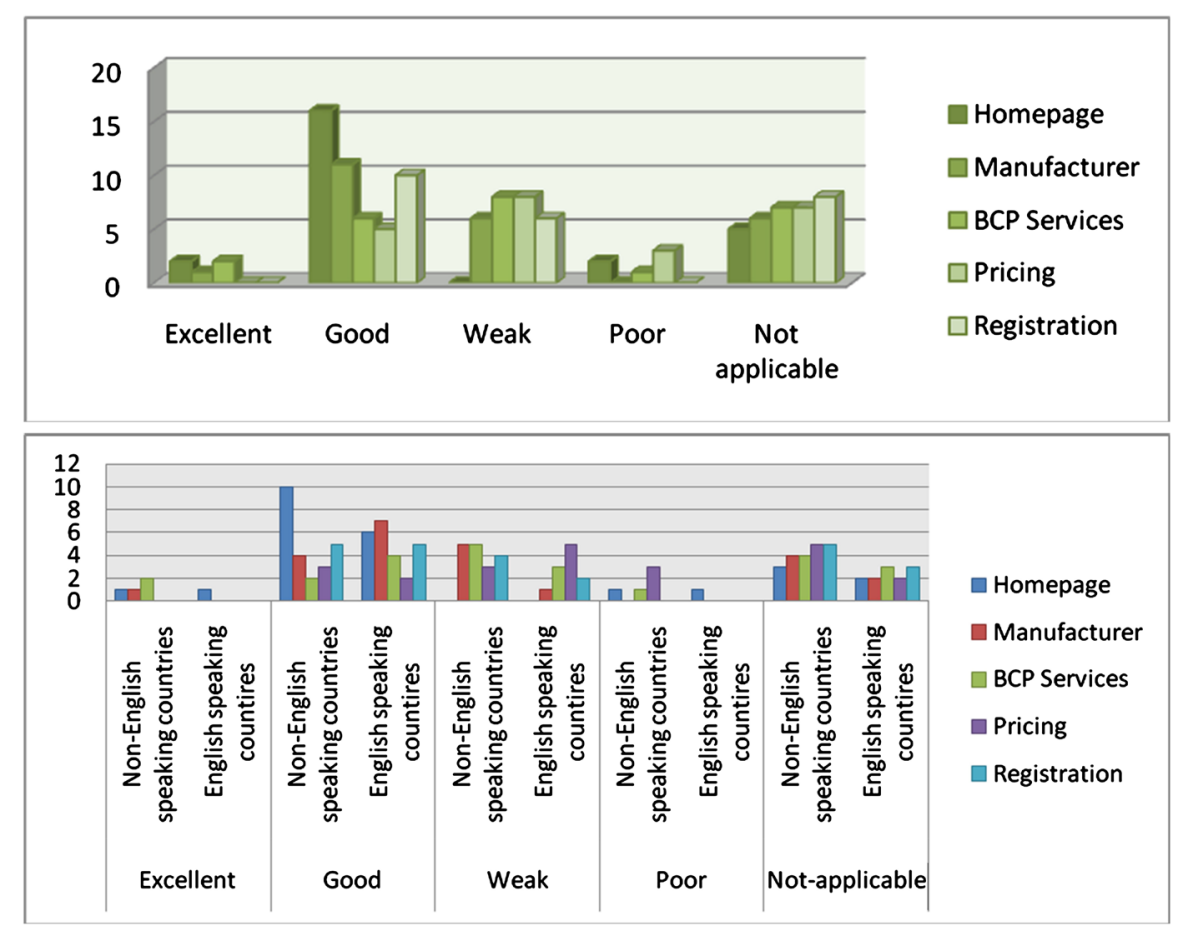

Source: Own Figure.

Figure 4. Starting from the homepage of BCP's website, please assess the navigation to the following pages from then on. 
nor formulated for a price sensitive customer group. When asked about the most popular ways of finding distributors, people selected the personal networking and recommendation from the colleagues. However, many respondents have realised the benefits of BCP's services.

At the same time, respondents have shown little/no interest in considering the "value for money", "use of contacts of BCP" and "relevant search categories" as important criteria for buying the services.

Cause 4: "An additional way to attract customers to register and subscribe is by providing the optional services"

The customers show a preference for optional services in Figure 6. The most popular options are: "references/recommendations of potential partners", "easy contact of featured of potential partners" and "discussion forums/networking with other registered users" which might prove effective in attracting customers. Additional services as suggested by one of the respondents which are beyond the capability of the company directly can be outsourced by partnering with the appropriate firm. E.g.: Partnership with consultants assisting companies to export who can supply clients with recommendations about their potential routes to market, including distributors.

Even though, no difference of choices have been reflected between the English

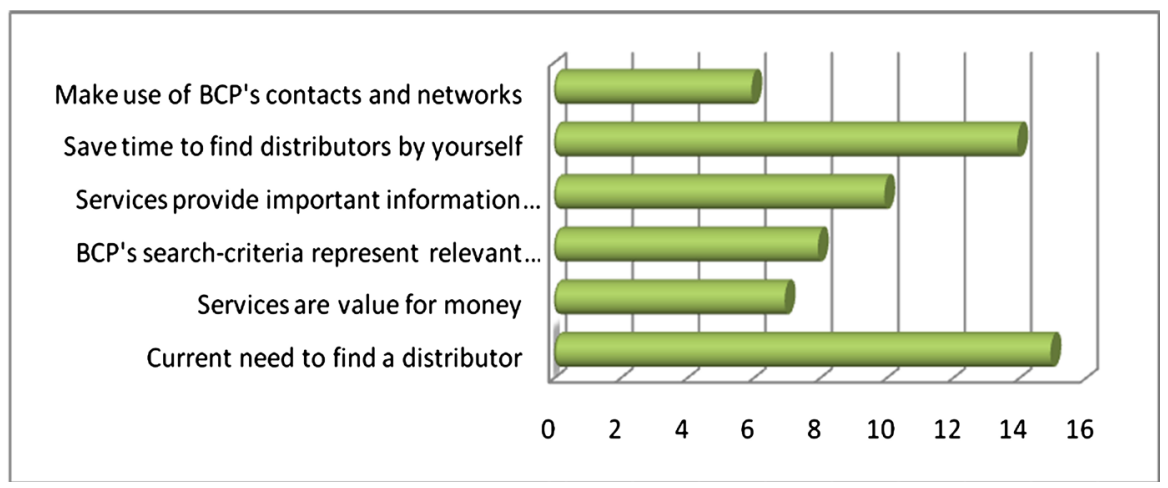

Source: Own Figure.

Figure 5. Presuming you consider using BCP's online search facilities to find distributors, under what circumstances are you likely to subscribe?

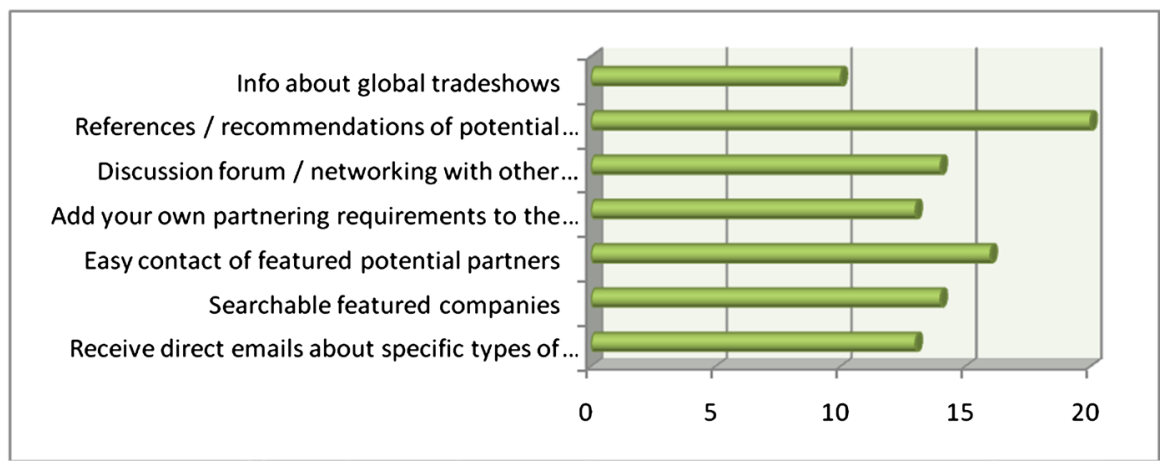

Source: Own Figure.

Figure 6 . What optional services would attract you to register and return to the website? 
and Non-English speaking countries from the survey responses, optional service such as translating the website in the local language can prove beneficial.

\section{Recommendation}

\section{Pro-active approach to actively target new customers}

The pro-active approach is based on the E-Marketing plan "SOSTAC", thus provides specific marketing recommendations for on-line companies [26]. As the name already indicates, SOSTAC comprises of several steps. The first step represents a situation analysis, which has already been conducted in the previous chapters. Second, specific marketing objectives need to be created, which indicate what needs to be achieved by the proposed actions. A strategy consisting of market segmentation, targeting and positioning along with customer retention and organisational adjustment strategy represents the next step. Afterwards, "tactics" of how to realise the positioning as well as the objectives will be suggested in form of the marketing mix (4Ps). An implementation plan will then clarify concrete actions for the upcoming time before in the end control measures will be proposed. The following Figure 7 visualises the single steps of SOSTAC.

\subsection{Situation Analysis}

The situation analysis is equivalent to the conclusions on the research phase, which derived major findings. These findings serve as the basis for the recommendations in the following paragraphs and are further summarised in the following Table 8.

\subsection{Objectives Regarding Marketing Activities}

The main objective of the project is to increase the sales turnover of BCP's on-line services that can only be achieved by increasing the traffic on the website. For that

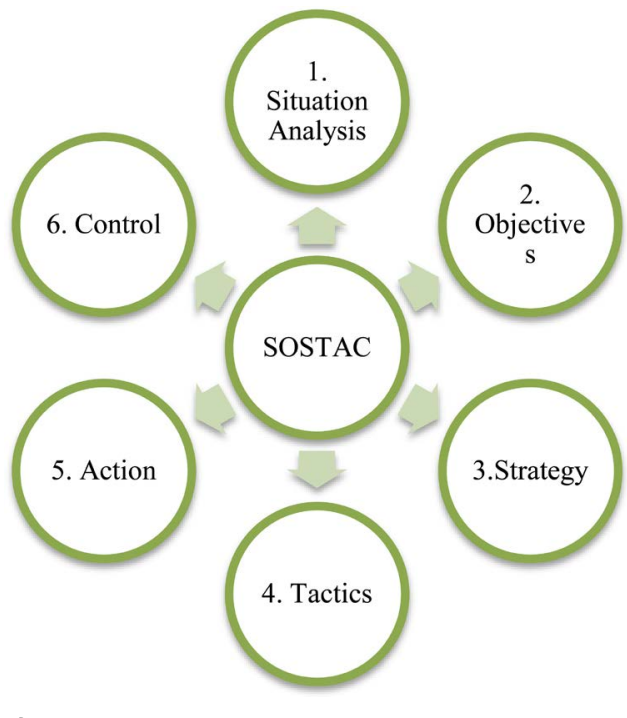

Source: Own Figure.

Figure 7. E-Marketing plan SOSTAC. 
reason several traffic specific objectives have been determined, which are displayed in Table 9.

The traffic specific objectives are expected to convert into sales increases for both on-line services. Since the services exhibit several varieties in terms of features, services and prices different sales-specific objectives have been set. In this context a total expected sale of 1615 Bronze credits over three years will lead to $£ 8715$ revenues. For BCP Silver, 78 purchases are expected that will generate $£ 62,300$ over the same time period. For the latter calculation only the minimum number of countries, thus three and five, have been selected (Table 10). The following Table 10 provides a breakdown of sales on a yearly basis.

Table 8. BCP-major problem areas.

\section{Major Problem Areas}

- Prevailing customer habits on personal contacts, networking and recommendations to find distributors

- BCP's on-line service Silver does not attract customers (value for money)

- Few usage of market research to consider customer demands/needs for important decisions like pricing

- Product benefits are not clearly communicated to potential customers - Web structure confuses issue even more

Source: Own table.

Table 9. Traffic specific objectives.

\begin{aligned} & \hline Time \multicolumn{1}{c}{ Traffic specific objectives } \\ & \hline - One person from $15 \%$ of the companies in the database to register (=1500 people) \\ & - 2000 visits per month by the end of year 1\end{aligned}

Source: Own table.

Table 10. Objectives focusing on revenue generation.

\begin{tabular}{cccccccc}
\hline \multicolumn{3}{c}{ BRONZE } & \multicolumn{7}{c}{ SILVER } \\
\hline Number of Credits & Year 1 & Year 2 & Year 3 & Number of Country & Year 1 & Year 2 & Year 3 \\
\hline 5 Credits & 5 & 10 & 20 & 1 country & 4 & 5 & 9 \\
20 Credits & 3 & 7 & 12 & 2 countries & 3 & 3 & 5 \\
50 Credits & 2 & 3 & 5 & 3 or 4 countries & 1 & 2 & 3 \\
100 credits & 1 & 2 & 2 & 5 up to 9 countries & 1 & 1 & 2 \\
\hline
\end{tabular}

Source: Own table. 


\subsection{Strategy}

\section{STP-Strategy}

Based on the industrial analysis, the group has identified three segments within the Life Sciences industry depending on the nature of the product. These segments are Pharmaceuticals, Biotechnology and Medical Technology, which can be further broken down into different product and application types (Figure 8). Although there is no outstanding growth of any particular sector, much attention is being paid on the Biotechnology sector by the governments across the world.

A geographical segmentation can be created in order to make the services more focused towards a particular region/country. USA is a major hub of the life science industry and Europe is also a strong market. Market in India and China are growing. $\mathrm{BCP}$ is advised to target all the aforementioned segments within the Life Sciences industry by concentrating on all product and application types that fall under each category. Molecular Biology under Biotechnology is considered to be of much relevance because of the demand for both manufactures and distributors in this category. Furthermore it is recommended that the company focuses on particular countries/regions. UK, Western Europe, USA are all strong markets to focus on. The online business should be extended to India and China. These countries are selected because of the industry analysis and they show the highest number of visitors on BCP's website (cf. Google Analytics). Individual marketing efforts can be directed as oppose to mass marketing towards these regions (cf. "Tactics" analysis).

The target customers of $\mathrm{BCP}$ are the manufactures following a strategy of international growth via distributors and/or are dissatisfied with their current distributors and/or plan to enter new markets (cf. BCP Business Plan) in each of these segments which at the moment constitute the $100 \%$ revenue generation source. Analysing the pricing preference of customers, two more groups within the manufacturers segment can be identified: first a more price sensitive group

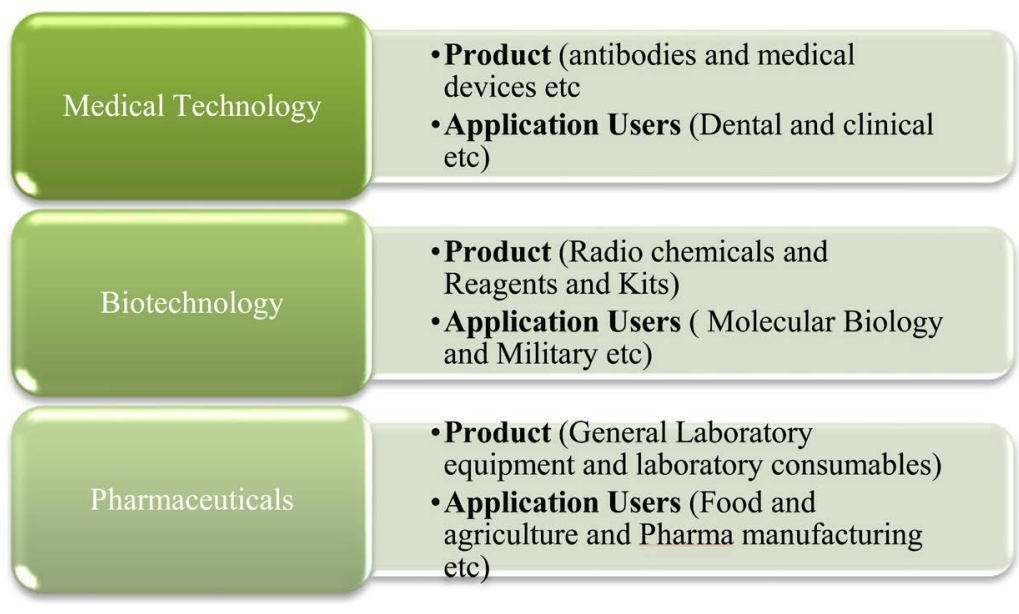

Source: Own Figure.

Figure 8. Segments, product and application types of the life science industry. 
for whom price is the sole reason for not buying the services and second, a less price sensitive group for whom there are other factors such as "no requirement for the services" that are more important, thus price is only a secondary factor. Prices and benefits of the services Bronze and Silver can be adjusted to meet the needs of both groups effectively.

Once the traffic on the website is high, there can be advertisement income. Further target customers might consist of Service Providers and Partners, which can be used for the purpose of promoting BCP's online services.

The positioning statement of $\mathrm{BCP}$ can be the one reflecting its core benefit and the needs of targeted customers in the best way possible:

"BioChannel Partners Ltd specialises in customised search and evaluation of distributors for the manufacturers in the life sciences and analytical laboratory field filtered and processed by an online database containing over 15,000 companies."

From the customer's perspective, the company has the most comprehensive database build on the contacts of Sharon Eaton. Moreover, the online services provide customised, filtered searches which is time-saving and hassle free looking from the perspective that search for distributor can be a most stressful and time-consuming job for the manufacturers.

What differentiates $\mathrm{BCP}$ from its competition is a unique business idea which is never floated or implemented in the Life Sciences industry before. Its services are completely different and new as compared to its indirect competitors which are the online directories (see the competitor's analysis for reference). Therefore, there are no direct competitors to the company which also gives it a first mover advantage and a competitive edge in view of its online services.

Since the next step of SOSTAC aims to propose communicational tactics to actively target new customers, the following part proposes actions to retain existing customers and to set up the organisation strategy accordingly.

\section{Retaining existing customers}

There are four key customer retention strategies to ensure that customers return to the website, which can keep traffic and the use of the services high.

1) Ask for feedback: Surveys, phone calls or e-mails can be utilized to gather feedback from customers. It is advisable that it should be done just after the delivery of the search results so that the most instant responses with relation to the services can be collected.

2) Expand service offerings: Expanding the service offerings can help to continue relationships with customers, who feel a need to tighten budgets. Such offerings can provide additional benefits like optional services.

3) Offer loyalty rewards: The rewards can be given in form of discounts/incentives/special offers, e.g. free Bronze credits for customers who have newly created their company, have registered to BCP and also to those who have been loyal customers of the company. BCP Silver test search could also be improved to become more appealing and beneficial. 
4) Lead the conversation: Discussions on social media is an effective way of interacting with customers. Interaction with a much larger audience consisting of people from non-English speaking countries on their local social media is also essential due to language barriers. Additionally, news alerts and e-mail updates regarding the latest industry news and advancement of BCP's services should be sent to the customers on the regular basis as well.

\section{Organisational adjustments}

Staff involvement will be crucial towards implementing the aforementioned strategies. Therefore certain organisational changes are suggested in the following:

Currently the company's staff is working part time. In order to successfully implement the suggested plan, employees have to work full time. In order to tackle the firm's inefficiency in carrying out business development and marketing activities, the aforementioned tasks should be allocated to employees. Once the company starts making progress, managerial and work-related positions should be included in the system. Important job positions like a web designer and an internet marketer could be appointed directly or outsourced.

\subsection{Tactics}

Product: Currently, BCP offers its on-line services exclusively on its website, which is the only point of sale. Therefore, the website is closely related to the services and should present, promote, convince and hence, support the sales of the services. Due to the close relationship, the website is regarded as a part of the services for the following recommendations.

According to primary research, BCP Bronze is perceived as value for money by all customers since it clearly communicates the service benefits, which is lacking in the website. Therefore, BCP is advised to revise its website to convince potential customers of its services by emphasizing on presenting service benefits clearly.

BCP Silver is currently not perceived as value for money by all customers. In order to capitalize on BCP's first mover advantage, Market research should be conducted to find what customers want to get out of BCP's unique database. BCP Silver should be adjusted and communicated accordingly.

In addition to current on-line services, BCP is advised to introduce optional services to increase traffic and the number of registrations/subscriptions. Such services compel the visitors to return more frequently and as a result they become familiarised with the entire website, services and increase the traffic. Referring to the primary analysis proposed optional services are as following Table 11.

Price: Currently, the pricing of BCP's on-line services is based on internal costs. Although they must be covered, attention should be drawn to the price sensitivity of customers especially in consideration of their prevailing habits to select distributors personally.

Place: By offering its services on-line to its global segments (cf. targeting), $\mathrm{BCP}$ must be able to answer queries, react to cultural differences and respond to purchases adequately no matter of variations in time and place. Hence, it is advised to adjust the central selling point: the website. Therefore, it is recom- 
mended to provide different language options. Additionally, customers suggested an instant delivery of services once purchased. It might be discouraging to wait 24 hours and thus, deferring search activities when they actually search at this particular moment. Such delay might also discourage further purchases. However, since 150,000 entries need to be verified the implementation might only be possible through computer systems.

Promotion: Promotional activities of BCP should aim to actively increase traffic on the website. In doing so, it is crucial to overcome the challenges associated with major problem areas. In this context the following paragraphs propose different recommendations that further include various communication tools of e-marketing activities (Figure 9 and Figure 10).

Table 11. Optional Services of BCP's website.

\section{Optional services}

- References/Recommendations of potential partners

- Easy contact of featured potential partners

- Discussion forum/networking with other registered users

- Searchable featured companies

- Addition of own partnering requirements to the website

- Receipt of direct emails about specific types of potential partners

Source: Own table.

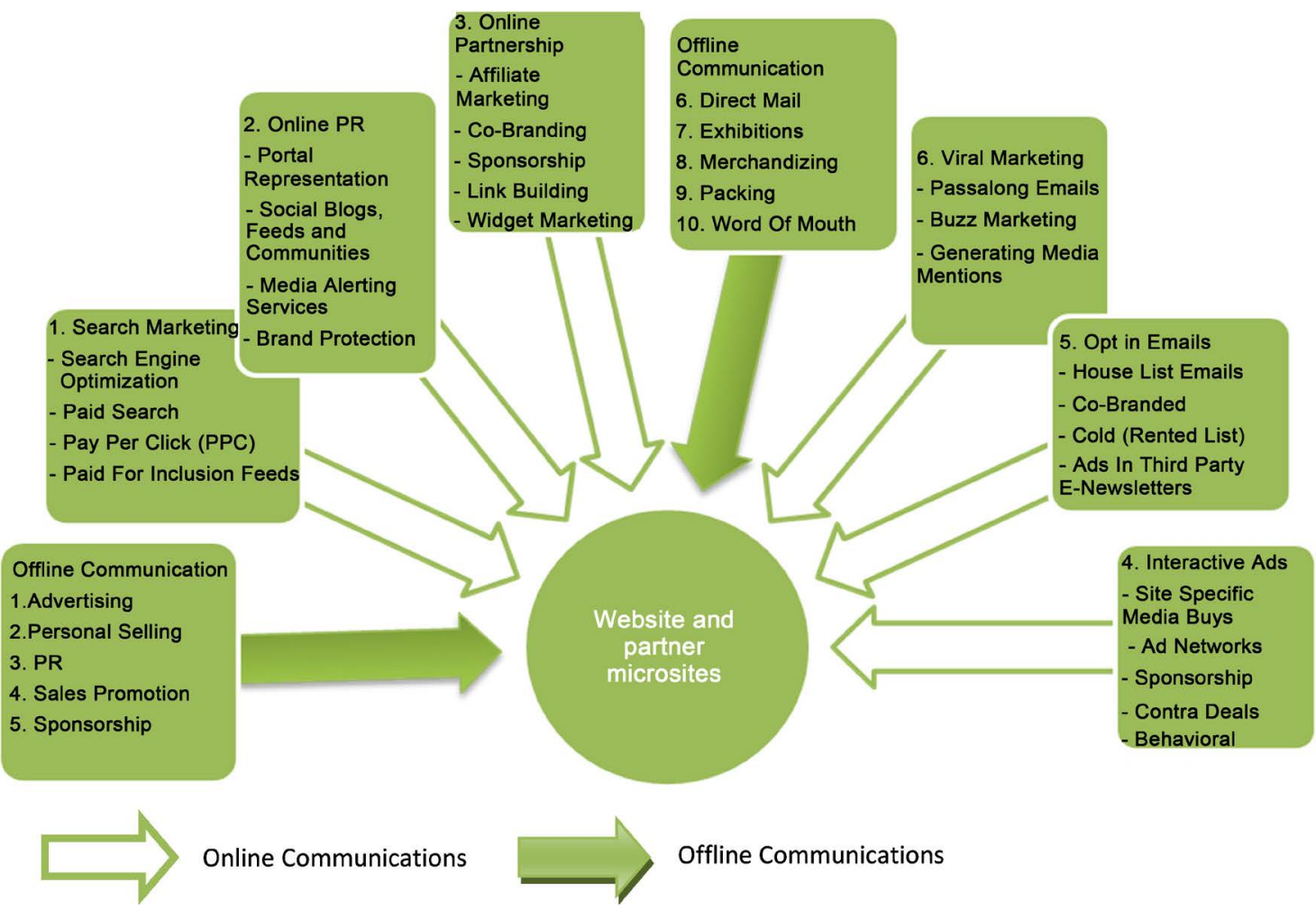

Source: Chaffey, 2009.

Figure 9. Communication tools E-marketing. 


\section{Recommendations}

1) Reduce uncertainty of customers to utilise on-line search services to find distributors

Prevailing habits of selecting distributors personally represent a major challenge that needs to be overcome by the communication strategy. It is advised to reduce uncertainties of customers as well as to convince them of the services. Thereby, BCP is advised to make use of testimonials, e.g. industry leaders and existing customers, on the website, on flyers and in direct e-mails who simultaneously point out the core benefits of BCP's on-line services. Product benefits and respective contributions to a customer's business should thereby be stated clearly. BCP should focus on exhibitions, trade fairs and on-line networks that represented the source of existing traffic, which leads to the second recommendation.

2) Emphasise on exhibitions, trade fairs and on-line networks to promote $B C P$ s services

Trade fairs, exhibitions and professional on-line networks represent the source of BCP's traffic as well as the basis for communication within the Life Science industry and hence, should be used more intensively. BCP is currently actively engaged on LinkedIn. Following the good results in terms of traffic generation and product promotion, the company is recommended to get actively engaged in other professional networks. In this context the Xing (Western Europe), Ushi (China) and Viadeo (global) provide opportunities to cover all targeted countries. BCP is advised to participate in two exhibitions and trade fairs per year that further covers the targeted countries successively. In this context for the first year the exhibitions Biotechnica in Germany, which is Europe's most meaningful exhibition in the Biotechnology and Life Science industry (Biotechnica, 2010), and "Life Science Alley's" $10^{\text {th }}$ annual conference in Canada are recommended (Lifescience Alley $10^{\text {th }}$ conference \& Expo, 2011). The activities in trade fairs are further advised to be supported by sales promotions. Since active commitment in on-line networks and exhibitions is required, it is suggested to employ a Business Developer on a fulltime basis.

3) Engage a full time business developer to conduct on-line and off-line communication

Besides utilising the Business Developer for the above mentioned activities, he/she should further conduct several on-and off-line promotions (Figure 10). Search Engine Optimisation (SEO) can attract new visitors. Almost all "referred visitors" of the website were redirected from Google. Hence, BCP is advised to optimise search engines to get under the first results for key words such as "manufacturer", "laboratory research tools" etc. BCP might consider SEO not only for Google, but also for Baidu to attract more visitors from China.

As the company does not face direct competitors it should focus on companies offering complementary products such as Labhoo. This might be realised in form of deferrals on the website, affiliate marketing, pay-per-click options (cf. STP strategy) or advertisement in e-newsletters. 


\subsection{Actions}

The following implementation plan summarises major actions, which have to be conducted to realise the recommendations made in the previous section. The plan is structured into three different parts, each showing concrete measures under a certain area. Further, it is shown, who is responsible for conducting a certain activity and when the aforementioned is advised to be completed. (cf. Blakely, 2010). The years are thereby divided into months. A full sized implementation plan is attached in Table 10.

Referring to Figure 10 the first measures consist of conducting research to adjust BCP Silver and respective pricing. Afterwards collected information can be included in the revision of the website, which is advised to be realised in collaboration with a web designer. Further, in June it is recommended to employ a full time Business Developer to start working on communication measures and to prepare the company's appearance for two exhibitions in the end of 2011.

\subsection{Controlling}

The purpose of monitoring is to check the progress of the marketing tactics and see if the main objectives set out earlier are on track to be achieved effectively. This also involves monitoring the customer awareness, customer satisfaction and customer attitudes. Additionally, the following Table 12 benefits come along with monitoring activities:

$\mathrm{BCP}$ can continue to use Google Analytic as well as its own website to keep

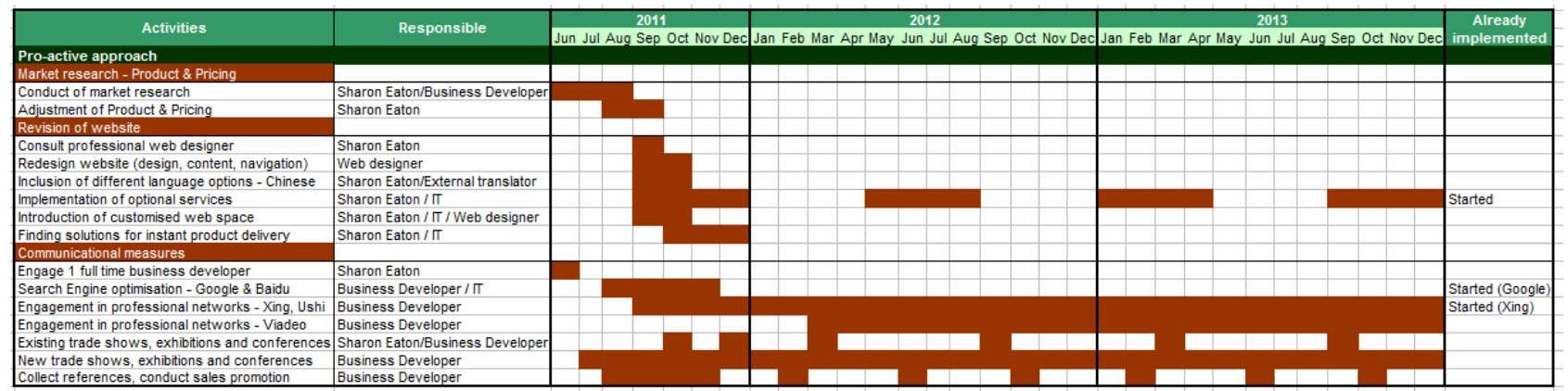

Source: Own Figure.

Figure 10. Implementation plan.

Table 12. Benefits of monitoring proposed recommendations.

Monitoring - Benefits

- First, it helps to assure that your efforts conform to the plan,

- To be sure that results achieved align with quantified objectives,

- Monitoring allows for corrective action,

- Since monitoring is part of a control process, it encourages improved performance,

- Finally, and most importantly, monitoring provides the essential link between the written plan and the day-to-day operation of your business.

Source: Own table. 
record of its progress both in terms of number of registration and subscriptions as well as overall traffic on the website. Similar to Google analytics, is another tool called BackType, which can be used for the same purpose. By entering BCP's website's URL BackType will show who's been linking to company's site on Twitter. It shows a graph with the number of mentions over the past week, a list of top influencers who have shared the address in the past month, and a list of latest tweets mentioning the URL. BCP can also compare their website to a competitors' URL.

Additionally, in the Internet there are several monitoring tools available that monitor customer feedback. The most beneficial ones are thereby Google Alerts, Twitter, Really Simple Syndication (RSS) and Google Reader as they are free of charge and provide valuable features.

\section{Conclusion}

The purpose of this paper is to increase the sales turnover of the newly introduced on-line services of BioChannel Partners Ltd. (BCP). The primary research and secondary research helped identify various negative issues affecting BCP's website. A few recommendations have been made to solve these issues in order to increase customer traffic on the website and in turn increase the sales of BCP. The website is missing a few necessary features and it isn't user friendly which affects the functionality of the website. Also, a complicated payment process and stages of finding distributors make the buying process unpleasant. Many people are unaware of the benefits of services provided by BCP, which calls for an effective marketing strategy. The website has unstructured information and navigation is tedious. In order to retain existing customers, their feedback is invaluable. Expanding service offerings, offering loyalty rewards, communicating service benefits are all effective means to retain existing customers. BCP is also in need for some organizational adjustments, such more full time employees, introduction of managerial positions, and recruitment or outsourcing of web designers and similar positions. BCP bronze is perceived as value for money service while $\mathrm{BCP}$ silver is not. Market research is required to find out customer needs and adjust BCP silver accordingly. Price sensitivity of customers has to be taken into account. Introduction of various optional services and promotional activities can also help increase traffic on the website. Since BCP's biggest obstacle is customers selecting distributors personally, BCP needs to properly communicate the benefits of using their services to the customer. Trade fair, exhibitions and online networks are appropriate mediums to promote BCP's services since these are bases for communication within the Life Science industry. Proper monitoring of marketing activities is vital to ensure its effectiveness. Customer awareness, customer satisfaction and customer attitudes also need to be monitored in order to track the success rate of achieving objectives.

\section{Conflicts of Interest}

The authors declare no conflicts of interest regarding the publication of this paper. 


\section{References}

[1] Hawn, M. (1996) Stay on the Web. MacWorld, 13, 94-98.

[2] Peterson, R.A., Balasubramanian, S. and Bronnenberg, B.J. (1997) Exploring the Implications of the Internet for Consumer Marketing. Journal of the Academy of Marketing Science, 25, 329-346. https://doi.org/10.1177/0092070397254005

[3] Long, J. (1997) E-Commerce: Doing What's Best for Business. Data Communication, 26, 77-80.

[4] Eichhorn, O. and Helleis, S. (1997) Cyberspace Cross-Selling. Credit Union Management, 20, 28.

[5] Kiang, M.Y., Raghu, T.S. and Shang, K.H.M. (2000) Marketing on the Internet-Who Can Benefit from an Online Marketing Approach? Decision Support Systems, 27, 383-393. https://doi.org/10.1016/S0167-9236(99)00062-7

[6] Kuan, H.-H., Bock, G.-W. and Vathanophas, V. (2008) Comparing the Effects of Website Quality on Customer Initial Purchase and Continued Purchase at E-Commerce Websites. Behaviour \& Information Technology, 27, 3-16. https://doi.org/10.1080/01449290600801959

[7] Vassilopoulou, K., Keeling, K.A., Macaulay, L.A. and McGoldrick, P.J. (2001) Measuring Purchasing Intentions for Internet Retail Sites against Usability Attributes. INTERACT: IFIP International Conference on Human Computer Interaction Conference Series, 76-83.

[8] Lindenberg, J. and Neerinex, M.A. (1999) A Generic Usability Test Environment for Web-Based Services. Ergonomic in Uitvoering Conference, The Netherlands, 12-13 November 1999, 1-6.

[9] Nielsen, J. (2000) Designing Web Usability: The Practice of Simplicity. New Riders Publishing, Indianapolis.

[10] Lecerof, A. and Paterno, F. (1998) Automatic Support for Usability Evaluation. IEEE Transactions on Software Engineering, 24, 863-888.

https://doi.org/10.1109/32.729686

[11] Al-Hawari, M. and Ward, T. (2006) The Effect of Automated Service Quality on Australian Banks' Financial Performance and the Mediating Role of Customer Satisfaction. Marketing Intelligence and Planning, 24, 127-147. https://doi.org/10.1108/02634500610653991

[12] Parasuraman, A., Zeithaml, V.A. and Malhotra, A. (2005) E-S-QUAL: A Multiple-Item Scale for Assessing Electronic Service Quality. Journal of Service Research, 7, 213-233. https://doi.org/10.1177/1094670504271156

[13] Chiu, H.C., Hsieh, Y.C. and Kao, C.Y. (2005) Website Quality and Customer's Behavioral Intention: An Exploratory Study of the Role of Information Asymmetry. Total Quality Management \& Business Excellence, 16, 185-197. https://doi.org/10.1080/14783360500054277

[14] Jin, B. and Park, J.Y. (2006) The Moderating Effect of Online Purchase Experience on the Evaluation of Online Store Attributes and the Subsequent Impact on Market Response Outcomes. Advances in Consumer Research, 33, 203-211.

[15] Shih, H.-P. (2004) An Empirical Study on Predicting User Acceptance of E-Shopping on the Web. Information \& Management, 41, 351-368.

[16] Shih, Y.Y. and Fang, K. (2006) Effects of Network Quality Attributes on Customer Adoption Intentions of Internet Banking. Total Quality Management \& Business Excellence, 17, 61-77. https://doi.org/10.1080/14783360500249661

[17] Chaffey, D. and Patron, M. (2012) From Web Analytics to Digital Marketing Opti- 
mization: Increasing the Commercial Value of Digital Analytics. Journal of Direct, Data and Digital Marketing Practice, 14, 30-45.

https://doi.org/10.1057/dddmp.2012.20

[18] Web Analytics Association (September 2008) Web Analytics Definitions. http://www.digitalanalyticsassociation.org/Files/PDF_standards/WebAnalyticsDefi nitions.pdf

[19] Nakatani, K. and Chuang, T.-T. (2011) A Web Analytics Tool Selection Method: An Analytical Hierarchy Process Approach. Internet Research, 21, 171-186. https://doi.org/10.1108/10662241111123757

[20] Järvinen, J., Töllinen, A., Karjaluoto, H. and Platzer, E. (2012) Web Analytics and Social Media Monitoring in Industrial Marketing: Tools for Improving Marketing Communication Measurement. In: Robinson Jr., L., Ed., Marketing Dynamism \& Sustainability: Things Change, Things Stay the Same... Developments in Marketing Science: Proceedings of the Academy of Marketing Science, Springer, Cham, 477-486.

[21] Blattberg, R., Buesing, T., Peacock, P. and Sen, S. (2010) Identifying the Deal Prone Segment. In: Allenby, G.M., Ed., Perspectives on Promotion and Database Marketing. The Collected Works of Robert C Blattberg, World Scientific, Singapore, 79-87. https://doi.org/10.1142/9789814287067_0005

[22] Brooksbank, R. (1994) The Anatomy of Marketing Positioning Strategy. Marketing Intelligence \& Planning, 12, 10-14. https://doi.org/10.1108/02634509410060695

[23] Devlin, J.F., Ennew, C.T. and Mirza, M. (1995) Organizational Positioning in Retail Financial Services. Journal of Marketing Management, 11, 119-132. https://doi.org/10.1080/0267257X.1995.9964333

[24] Porter, M.E. (1996) What Is Strategy? Harvard Business Review, 74, 61-78.

[25] Malhotra, N. and Birks, D. (2007) Marketing Research: An Applied Approach. 3rd European Edition, Pearson Education, London.

[26] Chaffey, D. (2009) E-Business and E-Commerce Management, Strategy, Implementation and Practice. Prentice Hall, Upper Saddle River. 